\title{
A comparative study of grasping-type scissors forceps and insulated-tip knife for endoscopic submucosal dissection of early gastric cancer: a randomized controlled trial
}

Authors

Institution
Kengo Nagai, Noriya Uedo, Takeshi Yamashina, Fumi Matsui, Noriko Matsuura, Takashi Ito, Sachiko Yamamoto, Noboru Hanaoka, Yoji Takeuchi, Koji Higashino, Ryu Ishihara, Hiroyasu lishi

Department of Gastrointestinal Oncology, Osaka Medical Center for Cancer and Cardiovascular Diseases, Osaka, Japan $\begin{array}{lll}\text { submitted } & \text { 2. February } 2016\end{array}$ accepted after revision 21. March 2016

\section{Bibliography}

DOI http://dx.doi.org/

10.1055/s-0042-105870

Published online: 12.5 .2016

Endoscopy International Open 2016; 04: E654-E660

(c) Georg Thieme Verlag KG

Stuttgart · New York

E-ISSN 2196-9736

\section{Corresponding author}

\section{Noriya Uedo, MD}

Department of Gastrointestinal Oncology

Osaka Medical Center for

Cancer and Cardiovascular Diseases

3-3, Nakamichi 1-chome

Higashinari-ku

Osaka, 537-8511

Japan

Fax: +81-6-6981-4067 uedou-no@mc.pref.osaka.jp
Background and study aims: Endoscopic submucosal dissection (ESD) for early gastric cancer (EGC) is technically difficult for beginners. Few comparative studies of technical feasibility, efficacy, and safety using various devices have been reported. This study evaluated the feasibility, efficacy, and safety of ESD for EGC $<2 \mathrm{~cm}$ using grasping-type scissors forceps (GSF) or insulated-tip knife (IT2) for three resident endoscopists.

Patients and methods: This was a randomized phase II study in a cancer referral center. A total of 108 patients with 120 EGCs were enrolled with the following characteristics: differentiatedtype mucosal EGC, without ulcers or scars, $<2 \mathrm{~cm}$ ( 86 men, 22 women; median age 72 years). All lesions were stratified according to operator and tumor location (antrum or corpus), assigned randomly to two groups (GSF or IT2), and resected by

\section{Introduction}

$\nabla$

Endoscopic submucosal dissection (ESD) for early gastric cancer (EGC) achieves high en bloc resection rates, and is regarded as a standard treatment for small $(\leq 2 \mathrm{~cm})$ intramucosal differentiated adenocarcinoma [1]. However, problems with ESD include a requirement for high expertise and prolongation of procedure time. When we investigated the difficulty of learning ESD for EGC $\leq 2 \mathrm{~cm}$ by supervised residents, we found that the self-completion rate was $60 \%$ and the procedure was particularly difficult during submucosal dissection [2].

In our hospital, an insulated-tip knife 2 (IT2; KD611L; Olympus Medical Systems, Tokyo, Japan) is used for gastric ESD because the IT knife was the first endo-electrosurgical knife that was developed for ESD, and its usage is the most established so far. However, it is often difficult for beginners to use the IT knife skillfully because its maneuverability is different from ordinary endoscopic devices such as biopsy forceps or puncture needles
ESD. Self-completion rate, complete resection rate, procedure time, and adverse events were evaluated as main outcome measures.

Results: There was no difference in self-completion rate between the IT2 group $(77 \%, 47 / 61, P=$ 0.187 ) and the GSF group (66\%,37/56). Also, there were no differences in en bloc resection rate $(98 \%$, $60 / 61$ vs. $93 \%, 52 / 56, P=0.195)$ and adverse events ( $3.3 \%, 2 / 61$ vs. $7.1 \%, 4 / 56, P=0.424)$. Median (min [range]) procedure time in the IT2 group (47 [33-67], $P=0.003)$ was shorter than that in the GSF group (66 [40-100]). Limitations of this study were the small sample size and single center design.

Conclusions: ESD with GSF did not show a statistically significant advantage in improvement of self-completion rate over IT2. (Study registration: UMIN 000005048)

that use the tip of the devices. Recently, a grasping-type scissor forceps (GSF; Clutch Cutter; DP2618DT; Fujifilm Medical, Tokyo, Japan) has been developed [3-7]. With this device, the targeted tissue can be grasped similarly to the biopsy forceps, and cut using an electrosurgical current. Therefore, we hypothesized that the GSF would improve self-completion rate and reduce the procedure time of gastric ESD for our residents.

The current study evaluated the feasibility, efficacy, and safety of GSF compared with IT2 for gastric ESD performed by supervised resident endoscopists.

\section{Patients and methods \\ $\nabla$}

Study design

This was a prospective, randomized, controlled trial performed in an endoscopy unit at the Osaka Medical Center for Cancer and Cardiovascular Diseases. The protocol of this study was approved by the hospital Institutional Review Board on No- 


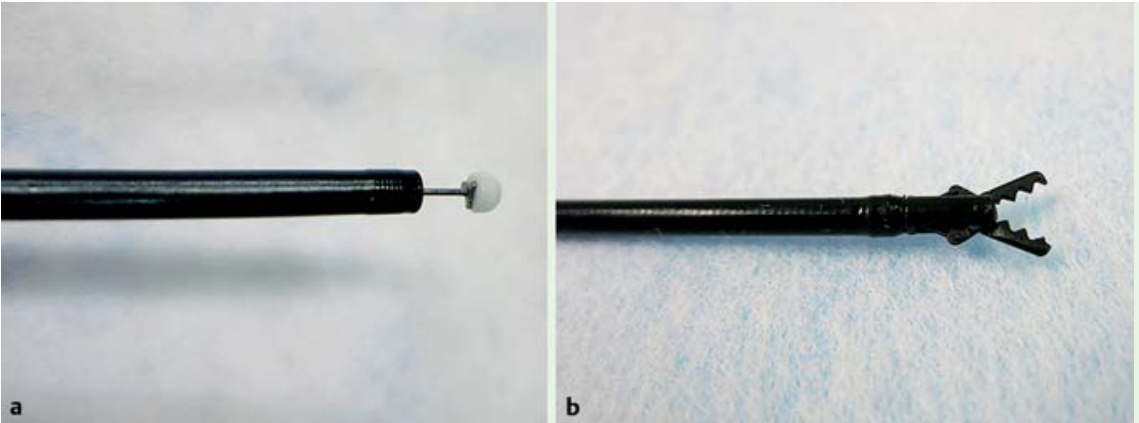

Fig. 1 a GSF. b IT2 knife.

vember 2, 2010 (No. 1011025109), and was registered in the University Hospital Medical Network Clinical Trials Registry (UMINCTR) as number UMIN000005048.

\section{Patients}

Eligible patients had adenoma or differentiated-type intramucosal EGC without ulcer or scar, $<2 \mathrm{~cm}$. Written informed consents for ESD procedure and study participation were obtained from all participants after explanation of the study design i.e. randomized allocation and characteristics of the 2 knives. Patients who had lesions located on the cardia or pylorus, severe organ failure, or coagulopathy were excluded. Antiplatelet agents were discontinued from 7 days before ESD.

\section{Operators}

Three resident endoscopists (K. N., F. M. and T. Y.) were invited to participate as operators. They had experience with $\geq 1,000$ regular esophagogastroduodenoscopy and >20 endoscopic mucosal resection procedures. Before starting this study, they attended a lecture about the techniques, reviewed videos by themselves, received hands-on training using a pig stomach, attended ESD procedures performed by experienced endoscopists for $\geq 6$ months, and had experienced ESD in 5 to 20 cases. All procedures were performed under the supervision of 1 of the experienced endoscopists (N. U., N. H., Y. T., K. H. or R. I.). The supervisors were changed under the following circumstances: over time, when time for each mucosal incision and submucosal dissection exceeded 1 hour; inability to control hemorrhage; perforation; and inability to continue the procedure, when the procedure could not be continued for reasons other than inability to achieve hemostasis or perforation.

\section{Devices and procedure}

ESD procedures were performed with patients under sedation using pentazocine (Pentazin; Sankyo Pharmaceuticals, Tokyo, Japan) and midazolam (Dormicum; Astellas Pharma, Tokyo, Japan). A videoendoscope (GIF-Q260J; Olympus Medical Systems) that was fitted with a disposable attachment (D-201-11804; Olympus Medical Systems) on its tip was used for all procedures. VIO300 D (ERBE, Tubingen, Germany) was used as an electrosurgical unit. Sodium hyaluronate (MucoUp; Johnson and Johnson, Tokyo, Japan) was used for submucosal injection. ESD consisted of: (1) marking areas for removal under $0.04 \%$ indigo carmine chromoendoscopic and magnifying narrow-band imaging observation; (2) circumferential mucosal incision outside the marking; and (3) submucosal dissection [8]. ESD techniques using GSF and IT2 were as follows.

The GSF ( $\bullet$ Fig. 1 a) had $3.5-\mathrm{mm}$ scissor-like serrated metal blades [3]. The outer side of the forceps was insulated to avoid electrical conduction to the surrounding tissue and so that electric current energy was concentrated at the inside of the blades. The forceps was rotatable in any direction. Marking was made with the tip of the GSF. After injection of sodium hyaluronate, mucosal incision was carried out outside the marking. The blades were perpendicularly applied to the mucosa for circumferential incision, while they were applied parallel to the mucosa during submucosal dissection. The mucosa or submucosa was grasped, lifted up, coagulated shortly with soft coagulation mode (Effect $5,80 \mathrm{~W}$ ), and cut in the endo-cut I mode (Effect 1, Cut duration 3, Cut interval 3, $\bullet$ Fig. 2).

The IT2 was a needle-type knife with a ceramic ball on its tip. Between the ceramic tip and a metal rod, there was a triangular metal plate that facilitated lateral mucosal cutting and submucosal dissection ( Fig. 1 b) [9]. Marking was carried out with a needle knife with forced coagulation mode (Effect 2, 30W). After precutting a hole with the needle knife to insert the tip of the IT2, mucosal incision was performed in the endo-cut I mode (Effect 3, Cut duration 2, Cut interval 3). Submucosal dissection was performed in swift coagulation mode (Effect 3,100W).

Oozing bleeding from a thin vessel was coagulated with GSF or IT2, whereas spurting bleeding from a thick vessel was stopped using hot biopsy forceps (Radial Jaw Hot Biopsy Forceps; Boston Scientific Japan, Tokyo, Japan) in soft coagulation mode (Effect 5, $80 \mathrm{~W})$.

The ulcer created after resection was carefully examined, and any visible vessels and adherent clots were coagulated by the hot biopsy forceps.

Resected specimens were pinned onto a hard Styrofoam plate and sent to the Department of Pathology for histological assessment of completeness of resection and curability. We considered the lesion to be curable when the following criteria were satisfied: (1) differentiated-type histology; (2) intramucosal cancer; (3) no ulcer or ulcer scar; and (4) no lymphatic or venous involvement. In the case of possible lymph-node metastasis evidenced by deep ( $>500 \mu \mathrm{m})$ submucosal invasion, lymphatic or venous involvement, the patients were subjected to gastrectomy with lymph-node dissection.

\section{Outcomes}

The primary endpoint was self-completion rate. Secondary endpoints were procedure time, en bloc resection rate, and completion rate. We considered that self-completion was achieved when there was no change of supervisor during all procedures. All cases were performed under the supervision of experienced endoscopists. The procedure time was measured from the start of marking until the end of tumor removal. It was divided into mucosal incision and submucosal dissection by the completion of the circumferential mucosal incision. Numbers of intra-proce- 


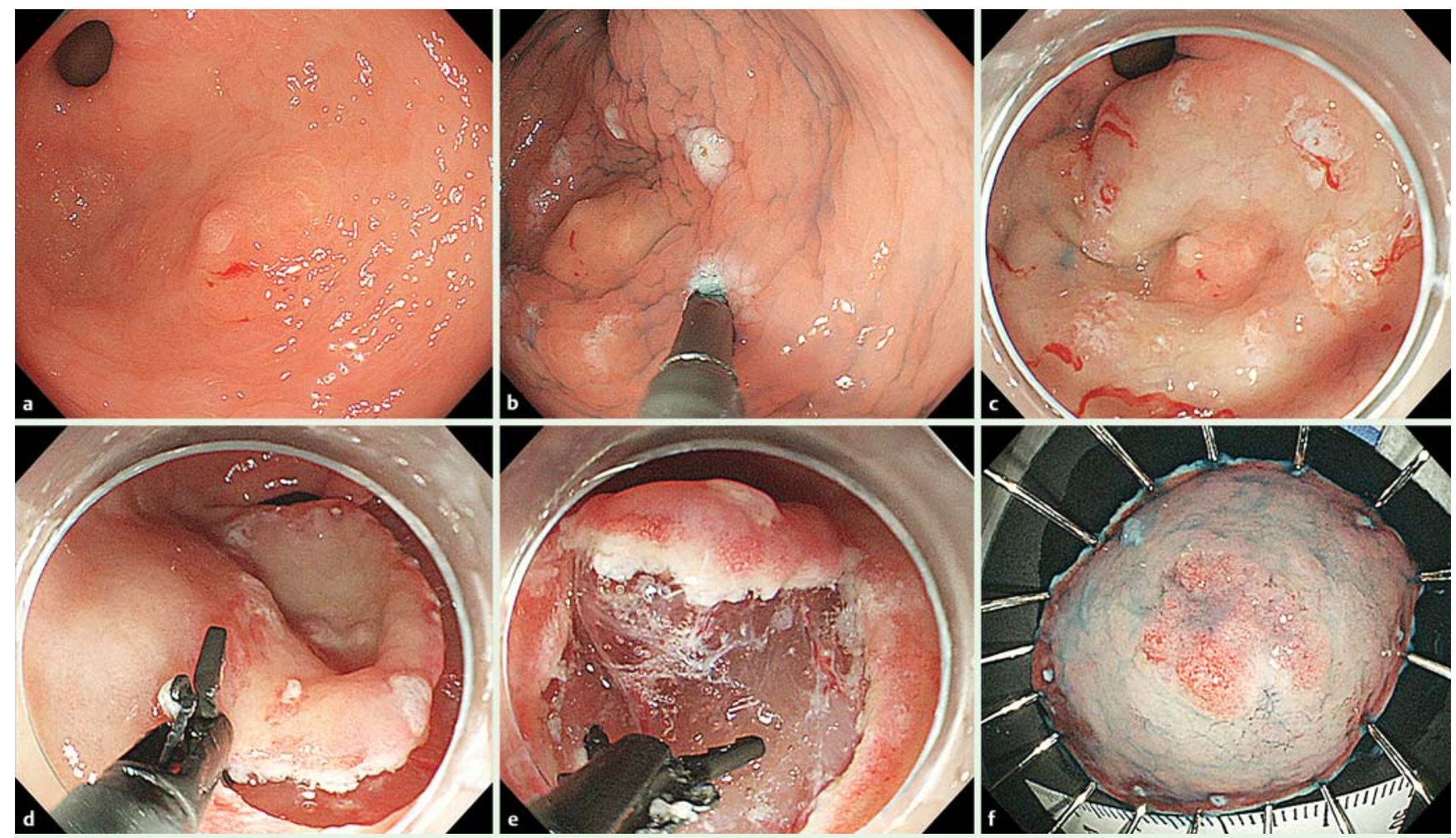

Fig. 2 a Chromoendoscopic observation: The depressed lesion $(\sim 10 \mathrm{~mm}$ diameter $)$ in the antrum was assessed, and chromoendoscopy with indigo carmine was used to assess tumor extent and depth. b Marking: We made marking dots $\sim 5 \mathrm{~mm}$ outside the tumor, with the tip of GSF using a forced coagulation mode. c Injection: We injected the submucosa outside the marking dots with sodium hyaluronate. $\mathbf{d}$ Making the initial hole and circumferential cutting: A hole was made outside the marking dots with GSF. One side of the GSF was inserted into the submucosa through the hole, and the mucosa was grasped, lifted up, coagulated shortly with soft coagulation mode, and cut with endo-cut mode. e Submucosal dissection: Submucosal dissection was performed with GSF in the same way. $\mathbf{f}$ Resected specimen: The specimen was pinned onto the Styrofoam plate for hisological assessment.

dural hemorrhage that required use of hot biopsy forceps for hemostasis were recorded. Complications included delayed bleeding and perforation that were greater than grade 3 according to the National Cancer Institute's Common Terminology Criteria for Adverse Events, version 4.0 [10].

\section{Sample size}

We assumed that the self-completion rate using IT2 would be $50 \%$, but that using GSF could improve this to $85 \%$. Power analysis indicated that $>49$ lesions were needed in each group, assuming a $5 \%$ significance level and statistical power of $80 \%$ using a two-sided equivalence. Therefore, we estimated that 60 lesions would be required in each group, taking into consideration eligibility deviation and dropout cases.

\section{Randomization and masking}

After stratification by an operator (either K. N., F. M. or T. Y.) and tumor location (antrum or corpus), 120 lesions from the study participants which fulfilled the inclusion criteria were consecutively assigned to 2 groups (GSF or IT2) according to a random number list. In this study, a lesion was considered as a unit of analysis, therefore, when a patient with $\geq 2$ lesions was randomized into both groups simultaneously, the device was changed and each lesion was treated by the allocated instrument. A random number list was generated using Excel 2010 (Microsoft, Redmond, WA, USA), and was preordered for each stratum. Operators were not masked to the treatment group.

\section{Monitoring of adverse events}

Adverse events (AEs) were evaluated daily by patient interview and physical examination during hospitalization, and were verified by patient interview at consultation at 2 weeks and 8 weeks after discharge. Patients were asked to contact immediately to the hospital if they experienced hematemesis, melena or severe abdominal pain. All ESD procedures and related complications were reported by the operators at a weekly conference. A complete blood cell count was assessed on the day after ESD, or if patients had fever, bleeding or peritonitis.

\section{Statistical methods}

Summarized data are shown as medians (25-75th percentiles) because the distribution was skewed. Self-completion, en bloc resection, and $\mathrm{AE}$ rates in the two groups were compared by $x^{2}$ test or, when appropriate, Fisher's exact probability test. Differences in the total procedure time and numbers of intra-procedural hemorrhage between the 2 groups were analyzed by Wilcoxon's rank test. A post hoc analysis using a logistic regression model was intended to elucidate the effect of the device on self-completion of ESD, and to identify other contributing factors to it. Candidate covariables included predefined strata (operator, tumor location) and statistically significant confounders with the selfcompletion by univariable analysis (size of tumor). Association between self-completion and confounding factors was analyzed by $\chi^{2}$ test. JMP version 9.0 software (SAS Institute, Cary, NC, USA) was used for data analysis. $P<0.05$ was defined as statistically significant. 


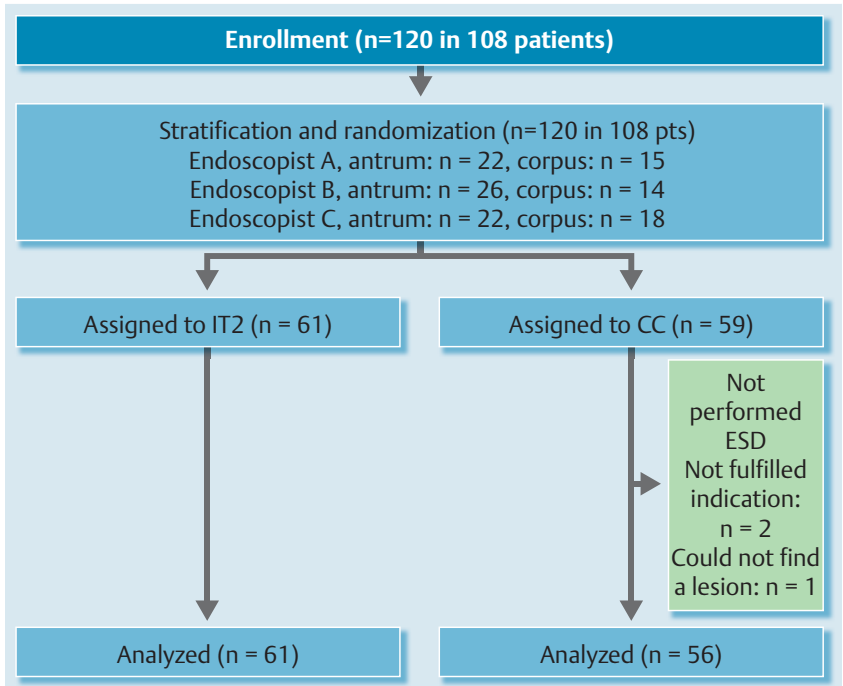

Fig.3 Flow diagram of the participants

\section{Results}

Participant flow and recruitment

Participants were recruited from September 2010 to April 2012. During the study period, 108 patients (86 men and 22 women, median age 72 years) with 120 EGCs were enrolled. Endoscopists A, B and C were stratified to antrum: 22, 26 and 22, and body: 17 , 15 and 18 lesions. Therefore, 61 lesions were assigned to the IT2 group and 59 to the GSF group ( $\bullet$ Fig. $\mathbf{3}$ ).

\section{Baseline data}

Baseline data for each treatment group are shown in $\bullet$ Table 1.

\section{Numbers analyzed}

In the GSF group, 2 lesions were found to be $>2 \mathrm{~cm}$ and the supervisor undertook the ESD procedure, and 1 lesion was diagnosed as submucosal cancer and ESD was discontinued. In total, we analyzed 117 lesions (61 lesions in the IT2 group and 56 in the GSF group).

\section{Outcomes and estimation}

Self-completion was achieved for 84 of 117 lesions in both groups. There was no difference in self-completion rate between the IT2 group ( $77 \%, 47 / 61, P=0.187)$ and GSF group $(66 \%, 37 / 56$,

- Table2). There was neither difference in the reasons to change to the supervisor nor in en bloc resection rate (98\%,60/61 vs. 93 $\%, 52 / 56, P=0.195$ ) between the IT2 and GSF groups. Median (interquartile range) procedure time (47 [33-67] vs. 66 [40-100] minutes, $P=0.004)$, mucosal incision time $(18[10-27]$ vs. 26 [18 -35] minutes, $P=0.004$ ) and submucosal dissection time (29 [17-40] vs. 39 [17-40] minutes, $P=0.005$ ) for ESD were shorter in the IT2 group than in the GSF group. The median number (interquartile range) of intra-procedural hemorrhage that required use of hot biopsy forceps in the IT2 and GSF groups were $1(0-3)$ and $2(1-3)$, respectively $(P=0.053)$. Complication rates $(3.3 \%, 2$ ) 61 vs. $7.1 \%, 4 / 56, P=0.424)$ did not differ between the two groups.
Table 1 Characteristics of the study subjects.

\begin{tabular}{|c|c|c|}
\hline & \multicolumn{2}{|l|}{ Device } \\
\hline & $\begin{array}{l}\text { IT } 2 \\
(n=61)\end{array}$ & $\begin{array}{l}\text { GSF } \\
(n=56)\end{array}$ \\
\hline Median age, years old (range) & $71(54-83)$ & $73(55-89)$ \\
\hline \multicolumn{3}{|l|}{ Sex } \\
\hline Male & 43 & 49 \\
\hline Female & 18 & 7 \\
\hline \multicolumn{3}{|l|}{ Operator } \\
\hline A & 19 & 19 \\
\hline B & 21 & 19 \\
\hline C & 22 & 18 \\
\hline \multicolumn{3}{|l|}{ Location of tumor } \\
\hline Antrum & 36 & 34 \\
\hline Body & 25 & 22 \\
\hline \multicolumn{3}{|l|}{ Macroscopic type } \\
\hline Elevated & 24 & 26 \\
\hline Depressed & 37 & 30 \\
\hline \multicolumn{3}{|l|}{ Median tumor size } \\
\hline (25 - 75th percentile, $\mathrm{mm}$ ) & $10(9.5-15)$ & $10.5(8-15)$ \\
\hline \multicolumn{3}{|l|}{ Histology } \\
\hline Adenoma & 5 & 4 \\
\hline Tub1 & 47 & 45 \\
\hline Tub2 & 8 & 7 \\
\hline No tumor & 1 & 0 \\
\hline \multicolumn{3}{|l|}{ Tumor depth } \\
\hline Intramucosal & 56 & 53 \\
\hline Submucosal & 5 & 3 \\
\hline
\end{tabular}

GSF, grasping-type scissors forceps; IT2: insulated-tip knife-2; Tub1, well-differentiated tubular adenocarcinoma; Tub2: moderately differentiated tubular adenocarcinoma.

\section{Ancillary analyses}

When we analyzed the contributors for self-completion, operators $(P=0.001$ for operators A vs. $B ; P=0.000$ for operators A vs. C) and tumor size $(P=0.024)$ were statistically significantly associated with self-completion by univariable analysis ( $\bullet$ Table 3 ). Multivariable analysis revealed that operators $B$ and $C$ (odds ratio [OR] 5.5 and 8.3, $P<0.001$ ) and small tumor size (OR 1.1, $P=$ 0.020 ) were statistically significant contributors to self-completion after adjustment for device, tumor location, macroscopic type, histology, and tumor depth ( $\bullet$ Table 4 ). The device was not an independent contributor to the self-completion rate (OR 0.59, $P=0.254)$.

\section{Adverse events}

One patient in the IT2 group and 2 patients in the GSF group developed delayed bleeding which was managed by endoscopic hemostasis. Perforation occurred during the procedure in 1 patient in the IT2 group and in 2 patients in the GSF group, but it was immediately closed by endoscopic clipping. All 3 patients completed the procedure and did not require surgical treatment. Overall, the incidence of each $\mathrm{AE}$ did not differ statistically between the 2 groups ( $\bullet$ Table 2$)$. 


\begin{tabular}{|c|c|c|c|}
\hline & \multicolumn{2}{|l|}{ Devices } & \multirow[t]{2}{*}{$P$ value } \\
\hline & $\begin{array}{l}\text { IT } 2 \\
(n=61)\end{array}$ & $\begin{array}{l}\text { GSF } \\
(n=56)\end{array}$ & \\
\hline Self-completion (\%) & $47(77)$ & $37(66)$ & 0.187 \\
\hline \multicolumn{4}{|l|}{ Reasons to change to supervisor (\%) } \\
\hline Overtime & $1(1.6)$ & $2(3.6)$ & \\
\hline Inability to control hemorrhage & $5(8.2)$ & $7(13)$ & \\
\hline Inability to continue procedure & $7(11)$ & $8(14)$ & \\
\hline Perforation & $1(1.6)$ & $2(3.6)$ & \\
\hline En bloc resection (\%) & $60(98)$ & $52(93)$ & 0.195 \\
\hline Median procedure time, min (IQR) & $47(33-67)$ & $66(40-100)$ & 0.004 \\
\hline Mucosal incision & $18(10-27)$ & $26(18-35)$ & 0.004 \\
\hline Submucosal dissection & $29(17-40)$ & $39(17-40)$ & 0.005 \\
\hline Median numbers of intra-procedural hemorrhage (IQR) & $1(0-3)$ & $2(1-3)$ & 0.053 \\
\hline Complication (\%) & $2(3.2)$ & $4(7.2)$ & 0.424 \\
\hline Delayed bleeding & $1(1.6)$ & $2(3.6)$ & \\
\hline Perforation & $1(1.6)$ & $2(3.6)$ & \\
\hline
\end{tabular}

Table 2 Primary and secondary outcomes.

GSF, grasping-type scissors forceps; IQR, interquartile range; IT2, insulated-tip knife-2.

\begin{tabular}{|c|c|c|c|}
\hline & $\begin{array}{l}\text { Self-completion } \\
(n=84)\end{array}$ & $\begin{array}{l}\text { Non-self-completion } \\
(n=33)\end{array}$ & $P$ value \\
\hline \multicolumn{4}{|l|}{ Device } \\
\hline IT2 & 47 & 14 & 0.187 \\
\hline GSF & 37 & 19 & \\
\hline Operator & & & 0.0001 \\
\hline A & 17 & 20 & \\
\hline B & 33 & 7 & \\
\hline C & 34 & 6 & \\
\hline Tumor location & & & 0.465 \\
\hline Antrum & 52 & 18 & \\
\hline Body & 32 & 15 & \\
\hline Median tumor size, $\mathrm{mm}$ ( $25-75$ th percentile) & $10(8-15)$ & $12(10-18)$ & 0.024 \\
\hline Macroscopic type & & & 0.966 \\
\hline Elevated & 36 & 14 & \\
\hline Depressed & 48 & 19 & \\
\hline \multicolumn{4}{|l|}{ Histology } \\
\hline Adenoma & 7 & 2 & \\
\hline Tub1 & 68 & 24 & \\
\hline Tub2 & 9 & 6 & \\
\hline No tumor & 0 & 1 & \\
\hline \multicolumn{4}{|l|}{ Tumor depth } \\
\hline Intramucosal & 79 & 30 & \\
\hline Submucosal & 5 & 3 & \\
\hline
\end{tabular}

Table 3 Confounding factors for self-completion, univariable analysis.

GSF, grasping-type scissors forceps; IT2, insulated-tip knife-2; Tub1, well-differentiated tubular adenocarcinoma, Tub2, moderately differentiated tubular adenocarcinoma.

Table 4 Adjusted odds ratio of variables for self-completion.

\begin{tabular}{|c|c|c|}
\hline & \multicolumn{2}{|c|}{ Multivariate analysis } \\
\hline & $\begin{array}{l}\text { Adjusted OR } \\
(95 \% \mathrm{Cl})\end{array}$ & $P$ value \\
\hline \multicolumn{3}{|l|}{ Device } \\
\hline IT 2 & 1 & \\
\hline GSF & $0.6(0.23-1.46)$ & 0.254 \\
\hline \multicolumn{3}{|l|}{ Operator } \\
\hline A & 1 & \\
\hline B & $5.5(1.9-17)$ & 0.001 \\
\hline C & $8.3(2.8-29)$ & $<0.0001$ \\
\hline \multicolumn{3}{|c|}{ Tumor location } \\
\hline Antrum & 1 & \\
\hline Body & $1.4(0.41-0.58)$ & 0.409 \\
\hline Tumor size & $1.1(1.0-1.2)$ & 0.020 \\
\hline
\end{tabular}

$\mathrm{Cl}$, confidence interval; GSF, grasping-type scissors forceps; IT2, insulated-tip knife-2; OR, odds ratio.

\section{Discussion}

In this prospective randomized study, there was no statistically significant advantage of GSF over IT2 for improvement in selfcompletion rate for gastric ESD ( $66 \%$ for GSF vs. $77 \%$ for IT2, $P=$ 0.187 ). Also, there was no difference in self-completion rate in both groups, even with correction with a stratification factor and a statistically significant confounder (OR $0.59, P=0.254$.)

This study demonstrated that gastric ESD performed by supervised residents was practical because the en bloc resection rate in both the IT2 and GSF groups was high: $98 \%$ and $93 \%$, respectively, and the AE rates were $3.3 \%$ and $7.1 \%$, which was similar to findings in our previous study [2]. Our resident endoscopists encountered difficulty and the procedure was taken over by the supervisor in some cases. Thus, the self-completion rate for IT2 in the current study was $77 \%$ and was almost equivalent to our previous data; the self-completion rate for GSF also was low. Our 
previous study revealed that control of hemorrhage during the ESD procedure was the key to improved performance of ESD. The reasons to change to the supervisor in this study were mostly inability to control hemorrhage and inability to continue the procedure associated with difficulty in controlling hemorrhage, and were similar between the groups. Although the GSF maneuver was more familiar to the operators than was IT2, because the targeted tissue can be grasped similarly by the biopsy forceps and cut, the incidence of hemorrhage during the ESD procedure requiring use of hot biopsy forceps was not reduced. Spurting bleeding from a thick artery was difficult to manage with GFS because the blades of the GFS were too thin to capture and coagulate the vessel effectively. Therefore, development of devices that can prevent or efficiently stop hemorrhage is anticipated.

The procedure time in the GSF group was longer than that in the IT2 group in the current study. Previous studies showed that gastric ESD using GSF required a mean operation time of 104 minutes for tumors with a mean size of $15 \mathrm{~mm}$ [7], whereas ESD with IT2 required a mean operation time of 48 minutes for a mean tumor size of $26 \mathrm{~mm}$ [9]. The main reason for the long procedure time for GSF was the difference in cutting processes between GSF and IT2.ESD using GSF required grasping and lifting the target tissue before cutting and dissecting it. In contrast, for IT2, the operators could cut and dissect the target tissue continuously when they became familiar with maneuvering the device. Also, it took time to rotate the GSF to the desired orientation, which was especially obvious during the retroflex scope position. We suspected that a simple mechanism and structure would eventually be suitable for the endoscopic devices, although some expertise might be needed to use them.

In our study, the self-completion rate was associated with operator and tumor size but not with device and tumor location in the multivariable analysis. Choi et al. have investigated the learning curve of a single endoscopist for ESD, and concluded that trainees need to perform 20 to 40 procedures to be able to use the technique effectively [11]. Tsuji et al. indicated that 4 training endoscopists showed $>80 \%$ self-completion rate, even in the early period of experience [12]. Gotoda et al. have suggested that experience with $\geq 30$ cases is required for a beginner to gain early proficiency in ESD techniques, according to their experience in training $>30$ endoscopists [13]. However, 2 of 3 operators in our previous study [2] and 1 of 3 operators in this study could not achieve a sufficient self-completion rate for ESD procedure after 30 cases. In our hands, an endo-knife with a water-jet function yielded reduced operation time with ESD [14], while other investigators indicated a water-jet knife prolonged procedure time [15]. This suggests that the learning speed of endoscopists varies widely and the device does not fully correlate with the technical skill of the endoscopists.

There were no differences in AE rates (3.3\% vs. $7.1 \%, P=0.424$ ) between the two groups in our study. In a case series by Akahoshi et al., there were no intraoperative complications and only delayed bleeding was seen in 3\% (1/35) of cases. However, we experienced perforation in 2 cases. The suspected reasons for perforation (especially with a perpendicular approach) were grasping of the surface of the muscularis propria with the submucosa or electrocautery damage when the tip of the GSF touched the muscularis propria. To prevent perforation, we accurate targeting should be confirmed while grasping and lifting the device from the resected base and before cutting. In other words, even a device that was created to be principally safe can produce AEs when it is used inappropriately.
So far, many ESD devices have been developed and are available for clinical practice in Japan. However, the advantages of one ESD device over others have not been fully investigated. We have shown that the short needle knife with water jet function [14] or nonconducting rotatable plastic shaft with cutting wire (Mucosectom, DP-D2518, HOYA Group PENTAX Medical, Tokyo, Japan) [16] can reduce procedure time for ESD. Although these studies indicated that some ESD devices have specific advantages, we believe that not all devices are superior. ESD devices are mainly classified as non-insulated type: Flex knife (KD-630L, Olympus Medical Systems), Dual knife (KD-650 L, Olympus Medical Systems), Hook knife (KD-620LR, Olympus Medical Systems), Flush knife (DK2618JN10 - 30, FUJIFILM Medical Systems, Tokyo, Japan), Hybrid knife (20150-261, ERBE Elektromedizin GmbH, Tubingen, Germany), TT knife (KD-620L, Olympus Medical Systems), etc., partially insulated type: IT-knife2, IT-knife nano (KD612L, Olympus Medical Systems), Mucosectom, SAFE knife (DK2518DV1 and DK2518DH1, FUJIFILM Medical Systems), etc., and scissor type: Clutch Cutter, SB knife (Sumitomo Bakelite Co., Ltd., Tokyo, Japan), etc. Non-insulated knives can cut tissue sharply but the speed of dissection of the submucosa is slower than with partially insulated knives [16]. Moreover, although a noninsulated knife is safe for gastric ESD in an expert's hands [17], when it is used by beginners, the risk of perforation may be higher during the learning curve [18]. Partially insulated knives can dissect the submucosa rapidly and have a low risk of perforation but maneuvering them is more complicated than use of non-insulated knives. Therefore, the non-insulated and partially insulated knives complement each other but the same type of knives have similar characteristics. The scissor-type knife, in this study, can be used for all steps of the ESD procedure including marking, mucosal incision, and submucosal dissection. The scissor-type knife was relatively safe, but the amount of tissue cutting or dissection was limited and the procedure took a long time. Although GSF did not improve the self-completion rate and required a long procedure time, we sometimes found that GSF could resolve difficult situations such as cutting fibrotic tissue in the narrow submucosal space better than IT2. Therefore, GSF could be beneficial as a rescue device for other knives.

This study had some limitations. First, although we invited 3 trainees as operators, this study was conducted at a single center in a restricted number of study samples. Therefore, to generalize the findings in this study and to clarify how many cases are required to achieve enough expertise for self-completion of ESD, further investigation is needed. Second, this study was designed to evaluate the superiority of GSF to IT2. Therefore, even if we failed to prove statistically significant superiority, we did not prove equivalence or inferiority of GSF to IT2.However, we regarded this as an exploratory study to select a better device that warrants further evaluation in a confirmatory study. Accordingly, we concluded that GSF is not the device to take over from IT2 because the self-completion rate with it was lower (GSF vs. IT2= $66 \%$ vs. $77 \%$ ) and the procedure time was longer.

In conclusion, although gastric ESD using GSF was feasible in terms of a high en bloc resection rate and low complication rate, there was no statistically significant advantage for GSF over IT2 for improvement of self-completion rate. In our practice, IT2 is still the standard device for gastric ESD.

\section{Competing interests: None}




\section{References}

1 Japanese gastric cancer treatment guidelines 2010 (ver. 3). Gastric Cancer 2011; 14: 113-123

2 Yamamoto $S$, Uedo $N$, Ishihara $R$ et al. Endoscopic submucosal dissection for early gastric cancer performed by supervised residents: assessment of feasibility and learning curve. Endoscopy 2009; 41: $923-$ 928

3 Akahoshi K, Akahane H, Murata A et al. Endoscopic submucosal dissection using a novel grasping type scissors forceps. Endoscopy 2007; 39 : $1103-1105$

4 Akahoshi K, Honda K, Akahane $H$ et al. Endoscopic submucosal dissection by using a grasping-type scissors forceps: a preliminary clinical study (with video). Gastrointest Endoscopy 2008; 67: 1128-1133

5 Akahoshi $K$, Akahane $H$. ESD using a newly developed grasping type scissor forceps for early gastrointestinal tract neoplasms. World J Gastrointest Endosc 2010; 2: 90 -96

6 Akahoshi K, Okamoto R, Akahane $H$ et al. Endoscopic submucosal dissection of early colorectal tumors using a grasping-type scissors forceps: a preliminary clinical study. Endoscopy 2010; 42: 419-422

7 Akahoshi K, Honda K, Motomura Yet al. Endoscopic submucosal dissection using a grasping-type scissors forceps for early gastric cancers and adenomas. Digestive Endosc 2011; 23: 24-29

8 Takeuchi $Y$, Uedo $N$, Iishi $H$ et al. Endoscopic submucosal dissection with insulated-tip knife for large mucosal early gastric cancer: a feasibility study (with videos). Gastrointest Endosc 2007; 66: 186-193

9 Ono H, Hasuike N, Inui $T$ et al. Usefulness of a novel electrosurgical knife, the insulation-tipped diathermic knife-2, for endoscopic submucosal dissection of early gastric cancer. Gastric Cancer 2008; 11: 47 - 52
10 National Cancer Institute Common Terminology Criteria for Adverse Events version 4.0. Available at: http://evs.nci.nih.gov/ftp1/CTCAE/ CTCAE_4.03_2010-06-14_QuickReference_8.5x11.pdf (Accessed: 17 May 2015)

11 Choi IJ, Kim CG, Chang HJ et al. The learning curve for EMR with circumferential mucosal incision in treating intramucosal gastric neoplasm. Gastrointest Endosc 2005; 62: 860-865

12 Tsuji $Y$, Ohata $K$, Sekiguchi $M$ et al. An effective training system for endoscopic submucosal dissection of gastric neoplasm. Endoscopy 2011; 43: $1033-1038$

13 Gotoda T, Friedland S, Hamanaka $H$ et al. A learning curve for advanced endoscopic resection. Gastrointest Endosc 2005; 62: 866-867

14 Takeuchi $Y$, Uedo $N$, Ishihara $R$ et al. Efficacy of an endo-knife with a water-jet function (Flushknife) for endoscopic submucosal dissection of superficial colorectal neoplasms. Am J Gastroenterol 2010; 105: $314-322$

15 Fukami $N$, Ryu CB, Said $S$ et al. Prospective, randomized study of conventional versus HybridKnife endoscopic submucosal dissection methods for the esophagus: an animal study. Gastrointest Endosc 2011; 73: $1246-53$

16 Kanzaki H, Ishihara R, Ohta T et al. Randomized study of two endo-knives for endoscopic submucosal dissection of esophageal cancer. Am J Gastroenterol 2013; 108: 1293-1298

17 Toyonaga T, Man-i M, East JE et al. 1,635 Endoscopic submucosal dissection cases in the esophagus, stomach, and colorectum: complication rates and long-term outcomes. Surg Endosc 2013; 27: 1000 - 1008

18 Teoh AY, Chiu PW, Wong SK et al. Difficulties and outcomes in starting endoscopic submucosal dissection. Surg Endosc 2010; 24: 1049-1054 